\title{
The Production of Service in the Digital City: A Social Informatics Inquiry
}

\author{
Elisabeth Davenport, Keith Horton \\ School of Computing, Napier University, Edinburgh, UK \\ e.davenport@napier.ac.uk; k.Horton@napier.ac.uk
}

\begin{abstract}
The authors discuss eGovernment as a computerization movement, and present a case study of a small project that was part of a modernising government initiative in a UK municipality. The case is analysed by means of an analytic construct, the technological action frame or TAF, that was developed by Iacono and Kling in 1998. This socio-technical approach provides distinctive insights at a number of different organizational levels.
\end{abstract}

Keywords: eGovernment, web of computing, computerization movement, technological action frame

\section{Introduction}

Though a human focus features strongly in the discourse of digital cities and egovernment, we suggest that the notion is ambivalent. An extensive literature gives accounts of the technical infrastructure, and the design rationale for augmentation, but fails to explore in detail the work of maintaining and managing the multiple layers of infrastructure that must be installed to meet the challenges of public service delivery. This hidden articulation work is in the hands of municipal officers whose agency is opaque. In contrast, consumer agency ('empowerment') is highly visible in digital city discourse, and, thereby, the agency of producers of commodities and services that satisfy consumer desire. Empowerment is also addressed in the context of civic communities, where agency is presented in terms of participation and membership. In both these cases (consumer and community), a utopian version of agency prevails, emphasising augmentation and engagement, increased opportunity and choice, and strength through cohesion.

However, in the digital city, as in any technology implementation, the infrastructure that 'empowers' or 'augments' one group may disempower others, or empower them in ways that they have not sought, though these anomalies and discrepancies are smoothed over in official versions of development. In the text that

Please use the following format when citing this chapter:

Davenport, E., Horton, K., 2006, in IFIP International Federation for Information Processing, Volume 223, Social Informatics: An Information Society for All? In Remembrance of Rob Kling, eds. Berleur, J., Numinen, M. I., Impagliazzo, J., (Boston: Springer), pp. 233-242. 
follows, we present the case of a group of municipal service workers whose work has been transformed in a series of digital city projects financed by national 'egovernment' funding. We track the ambivalent agency of this group using a social informatics lens, computerization movements, that was developed in a series of studies by Kling and his colleagues (e.g. Kling \& Iacono 1994; Iacono \& Kling, 1998) for twenty years or so.

\section{2 eGovernment as a Computerization Movement}

Choices and decisions surrounding information technology acquisition and configuration are rarely straightforward, but in the UK public sector these can often involve the spending of hundreds of thousands, or millions of pounds over the course of a project. There is considerable scrutiny and reporting of such practice, often unfavourably. Increasingly, public services are faced with tasks involving information service integration, which in essence is concerned with addressing complex technology needs with particular configurations of technologies that reflect, and are reflected in the socially and historically situated nature of the proposed usage (Fleck, 1993). This is not acknowledged however in the rhetoric of integration that drives projects, and that is premised on the deterministic assertion that institutional activity can be 'modernised' through the introduction of ICTs (Cabinet Office, 1999).

A national agenda for e-government in the UK has emerged from two historical trends. The first is a privatization movement that has evolved over almost twenty years, starting with the publication of a UK government report in 1986 that paved the way for the privatisation of government data, and the establishment of an industrygovernment nexus that has continued to expand under both Conservative and New Labour administrations. In addition, an uncompromising deployment of e-commerce and business models and applications has produced a service ecology dedicated to improved efficiency and quality of service which can as easily support private as it does public administration. E-government in the UK thus promotes itself as processoriented and customer-focused. The second trend is modernisation, a policy that also emerged in the 1980s and seeks to ensure that public services are 'joined up' and strategic, 'responsive to citizens', and 'high quality and efficient' (Cabinet Office, 1999).

Such utopian visions are characteristic of computerization movements (CMs), the powerful social informatics concept that is introduced above. The studies of technology in organizations that underpinned the evolution of the concept shared a common feature - a dissonance between the expected and the actual outcome of projects. This could be explained, suggested Kling and Iacono (1994), by the fact that the goals of many projects were ideological as much as technical, with systems seen as 'instruments to bring about a new social order'. CMs 'communicate key ideological beliefs about the favourable links between computerization and a preferred social order which helps legitimate relatively high levels of computing investment for many potential adopters. These ideologies also set adopters' expectations about what they should use computing for and how they should organize access to it' (Kling and Iacono, 1994, p. 3). In addition to articulating ideologies, CMs are a means of setting 
agendas. Kling and Iacono present a number of societal computing initiatives as examples of $\mathrm{CMs}$ - artificial intelligence, home computing and remote working.

As we note above, e-government projects in the UK are driven by two ideologies, privatisation and modernisation. These are tightly coupled through what are known as 'public private partnerships', whereby design and implementation are outsourced to commercial companies. Along with central government, they are key players in setting an agenda for modernising government. Design and implementation reinforce the ideology of efficiency by employing standardised proprietary protocols that pay scant attention to participative requirements analysis, and smooth the lumpy texture of organizational social life, leaving little or no room for the negotiation and adjustments that collaboration inevitably requires (Davenport, 2004). The elision of the local and the social is consolidated in norms for evaluation within project planning protocols, as these are rigorously constrained to address the validation of pre-scribed functions and features. Emergent and contingent localised behaviour is thus construed as problematic - the phenomenon of the 'problematization of the user', explored in depth by Lamb and Kling (2003)'. In addition, the current trend in e-government (and organisational computing generally) is to assemble components designed and validated elsewhere these exogenous assemblages have emergent local effects that are not acknowledged in the utopian planning stages of project planning.

The original completion date for the construction of an integrated UK infrastructure (all services integrated by 2005) has not been fully achieved, and there have been repeated over-runs in terms of time and budgets. Yet, puzzlingly, contracts have continued to be awarded to a small group of providers, few of whom have been called publicly to account. We suggest that the puzzle can be explained with a detailed $\mathrm{CM}$ analysis, using one of Iacono and Kling's (1998) key concepts, the technological action frame.

\section{Technological Action Frames}

According to Iacono and Kling (1998), 'participants in computerization movements build up frames in their public discourses that indicate favourable links between internetworking and a new, preferred social order...changes in worklife are shaped (but not determined) by the prevalent discourses informing new technologies and the practices that emerge around them in actual workplaces' (p. 4). They describe this phenomenon as a technological action frame (TAF). This notion is an amalgam of two concepts. The first is the sociological concept of framing, presented by Goffman in 1974 and elaborated by analysts of social movements such as Snow and Benford (1992), who present 'collective action frames' (CAF) as a political instrument, a means of aligning support and resources, and consolidating power. CAFs specify what is in the frame and what is out of the frame - one set of meanings rather than another is conveyed, or one story rather than another is told; CAFs are thus is 'more agentic and contentious' (Snow, 2004) than everyday interpretive frames. The second feeder concept is the 'technological frame' (TF) developed in the socio-technical analyses of Bijker (1997) and Orlikowski and Gash (1994) to explain ways in which technology is perceived and appropriated in different contexts. Technological frames are an effective 
unit of analysis that supports explanation of the unintended consequences of organizational computing. The TAF, according to Iacono and Kling, combines the explanatory power of TFs and political power of CAFs and explains how groups achieve authority and legitimacy, and marginalise opponents. A strong TAF, or 'master frame' stabilizes a set of key meanings for a focal technology' (Iacono and Kling, 1998, p. 8).

As we note above, the provision of e-government services in the UK is dominated by a few very strong players who have links to the relevant networks in central government, local government, private sector vendors and consultants, and citizen groups. This elitism is manifest in the small and oligopolistic market that has developed for e-government service implementation, where repeated contracts are awarded to large corporate developers whose previous contracts have not been delivered either to budget, nor on time or to a performance standard that satisfies agreed criteria. ${ }^{2}$ Members of the elite group share and maintain the master frame, a 'winning' discourse that draws its strength by association with proven players, who offer 'integrated off-the-shelf solutions' in the form of implementation plus training and economies of scale that undercut the costs of those involved in detailed local user requirement analysis. ${ }^{3}$ In the case study that follows we explore 'mobile working', the most recent of a series of modernization initiatives in a small municipal service group.

\section{The Rapid Response Team Case Study}

The case that is reported here is not untypical of many ICT initiatives in UK municipalities where a local council seeks to embrace the modernising of its activities through the utilisation of, in this instance mobile, ICTs. The Council in this case (a Scottish municipality) aimed to have " $30 \%$ of peripatetic staff ... mobile working by 2005" (Council, 2004). Whilst this broad aim was 'at the back of the mind" ${ }^{4}$ of some senior staff with an interest in ICT utilisation, it was the unforeseen availability of $£ 200,000$ that prompted the decision to introduce mobile ICTs into several areas of work. (This is an example of the opportunism that sometimes consolidates collective framing). Negotiations with the council's outsourcing partner (one of the big consulting firms that constitute the elite in UK e-government contract work), with whom the council have a ten year partnership agreement for provision of ICT services, led to the identification of both technologies and services that could be introduced. Discussions within the council management team identified the areas work to which the new ICTs could best be applied.

One of the areas identified was a social services rapid response team. The Rapid Response Team (RRT) is a small unit of six people who normally operate in pairs, and are responsible for community care. They work with clients, often at short notice, to provide support services and equipment that will allow the client to remain living within the community (as opposed to moving into a hospital, or other form of institutional care facility. In spring 2004 we were invited to undertake a quick and dirty evaluation of a pilot project to assess the potential of mobile technologies in the RRT. Team members were issued with notebook and tablet PCs, and given access to a 
(limited) number of information services, and canvassed for their opinions. Our study ended at the beginning of 2005 .

\subsection{The Official Version}

According to the vendors and the council policy-making team, the project was a success. After the six month pilot study, an evaluation was undertaken by the outsource partner, and published (internally only). In terms of CM analysis, this can be seen as the confirmation of a TAF (modernization, efficiency) by the dominant stakeholders in the project. The criteria in the evaluation were restricted (a typical manoeuvre in the discourse of justification in computerization movements), having been defined by the outsource partner, and evaluation focused solely on the Return on Investment. The outcome of this evaluation was the calculation of a time saving of $10.4 \%$, and a net 'productivity saving' of $£ 2280$ per worker per annum. This evaluation document directly supported the ideology of modernization - it described a 'successful' pilot project, with a demonstrable financial benefit. The document was circulated within the council, and played an important part of the discussion of an extended roll-out of mobile technologies, and integration of information services across further groups within the council.

\subsection{The View from the Ground}

But the story from the frontline was different. In our 'unofficial' evaluation, members of the RRT raised a number of 'issues and concerns' (Kling \& Scacchi, 1982). The first of these was technology. There were significant differences in the experiences with the technologies used (from three different suppliers). Frontline RRT workers liked the functionality on offer, though perceptions of reliability and battery life were a key factor in determining whether a technology was used in the field, as they would not take the chance of a technology failure impairing the interaction between themselves and their clients. The ability to utilise the mobile technologies with the client in-situ, was viewed as providing a speedier, and thus enhanced level of service (i.e. enabling more people to be independent in the community). The official evaluation did not pick this up: the criteria used by RRT members (client and humancentred) were outside the frame of cost efficiency. But though mobile technology was accepted in principle, there were problems with integrating information services. The issue here was the importance of access to both key information (e.g. client file, stores), as well as to communication services (e.g. email, fax) for mobile working to be feasible. In addition, it was not possible to utilise electronic versions of the forms that RRT members had to complete and share with other agencies, noting that it was "a shame that no-one had ever thought about using the forms electronically or delivering them electronically when they were designed ... which seems crazy".

Contrary to comments made in the official evaluation of the pilot project (Evaluation Paper, issue 1.0, p.51), there was a perception in the RRT that the technology was "a solution thrown over the wall". This was reinforced by perceived lack of consultation about process, as well as about technology requirements. Lack of training in the early stages meant that technology functions were not maximised. This 
reflected a general disquiet about the consultation that had taken place, with Team members commenting for example, "They did it back to front ... it would have been nice if they'd asked us what we needed, but instead they imposed it on us".

Frontline workers were frustrated by the lack of attention to a complex of work practices that is characteristic of RRT work, or what may be described as the 'production lattice' (Kling \& Scacchi, 1982) of service delivery. Though the mobile technology enabled some remote working (i.e. undertaking a task from a 'remote' location) ultimately, the RRT's activities remained unaffected by the introduction of the mobile technology. While access to the mobile technologies meant that RRT members felt able to meet up with their own team, and other team members while out of the office (e.g. a client's home to complete an ABC form), this did not affect significantly the time they spent in/away from the office. RRT members spend only $50 \%$ of their time on Rapid Response duties: the other $50 \%$ of their duties ("picking up cases' within the office) was not affected by the project.

Historically, the social work team has worked from a local council office, where cases are picked up and discussed, where expert judgment is exercised, and where much of the coordination of services from different agencies is arranged. Work in the office is interspersed with home visits, where initial assessment can be discussed with colleagues back at the office before a plan of action is agreed. Traditionally, one might say, a response by the RRT is 'configured' in the office after a more or less lengthy series of moves and deliberations. The response team are qualified professionals, and office meetings are also occasions for exchanging and updating knowledge, alerting colleagues to new developments, and discussing client circumstances 'off the record'. The mobile initiative will diminish information exchange in the team, as it is intended to shift this part of the process to the client's home, where an individual client and one, or two individual team members can configure what is required on the spot, in a process of in situ consultation and coordination. The configuration that is agreed will be entered on the relevant form, and activates a series of data transactions - the configuration is compiled, the relevant resources are coordinated and a response is composed that indicates what will arrive when. While this may 'augment' service for an individual client, as they may be given material support sooner by means of the digital service than in the traditional service, we suggest that understanding of service across the community may be diminished.

\section{Discussion}

We suggest that an important question that is rarely asked in the context of modernisation and visions of virtual services in e-government is 'where and when and by whom does a response get made'. Such issues of material realisation underlie the effective exploration of agency. Those who commission and design virtual services (for example, senior service managers) will respond: 'by means of an integrated transaction process that is mostly handled within an IS'. This fits well with the TAF that drives prevailing policy in the municipality, a response, as we imply above, to a mandatory UK 'modernising government' initiative, which has introduced the dehumanized concept of the 'managed citizen' into council thinking. The management 
of citizens is achieved by means of process modelling that combines representation of services and representation of individual profiles. There is little room in this componential model to apply the collaborative knowledge of grounded professionals (the output of sometimes messy and contested negotiations and consultations in the RRT office), as it is premised on the satisfaction of an abstract profile of consumer 'needs' The TAF or master frame takes little account of the micro-geography of expert social care work, as the 'workers' are modelled as ancillaries, whose location when they input, retrieve or report is of little interest.

If the question is asked of the frontline social care workers, the response comes from a different frame, one that is based on humanistic notions of interaction, solidarity and shared practice. From this perspective, the response emerges over time (one might compare the 'process' and 'human' versions of rapid response with 'fast' and 'slow' food), and happens in multiple locations where people interact, in the 'interspaces' (Crabtree, 2000) between technologies. It is supported by a number of activities and events, more or less computerised (some data is entered into databases, some is held in notebooks and folders of case notes) and more or less mediated (by email, telephone). The communal office is the primary site for picking up cases, and checking on their progress, and eliciting help from colleagues when cases get out of hand. Places in the sense of 'articulated moments in networks of social relations and understandings' (Massey, 1993) are thus important in the work of the RRT, as the 'response' is a socio-technical interaction, not merely a computerised transaction. This frame was not, at the time of our inquiry, politicized, and thus conferred little power on those adhering to it.

However, the 'process imperative' that characterises modernising government initiatives across the UK is closely coupled with visions of the elision of space: it is quite literally 'utopian'. The mobilisation project is not exempt, as the city council intends to make savings on real estate by closing some local social services offices. Some RRT members may become migrant or nomadic workers who must find space where they can, and operate as dispatchers rather than flexible specialists; they will occupy the 'non-spaces' (Auge, 1995) that characterized the late twentieth century; malls, cafes, car parks, where memory has no purchase and transience is the prevailing experience (This vision may be compared with that of Iacono and Kling in a discussion of the 'death of distance' TAF, 1998, p. 14). If this scenario is realized, it may be that RRT members will mobilize support from their professional bodies and their trade unions and from a competing action frame.

\section{Conclusion}

Our starting point in this paper was the unequal and shifting nature of power in the digital service arena. We have briefly presented the positions of two of the agents involved in an e-government pilot study (senior managers and social care workers in the form of the rapid response team and the council information services directorate). To explain the happenings in the case that we present above, a CM framework using TAF analysis provided insights at different levels of organization ${ }^{5}$.Firstly, TAF helped us clarify the dynamics of implementation in a way that a less ambitious TF analysis 
would not have achieved. If the case is seen as a specific example of a computerization movement (e-government), where a master TAF is at work then some puzzling features can be explained. These include the lack of local requirements analysis and the arbitrary provision of functionality in the pilot project for 'mobile working'.

Secondly, by focusing on what is outside the TAF, a researcher or manager can find out where and why resistance happens in the form of tweaking and work-arounds. Such apparent inefficiencies may contribute to effective service, and can be grounds for negotiation and development. Thirdly, a CM/TAF approach embeds the case in a historical trajectory of government computing initiatives over a period of 20 years, that in aggregate, constitute the master frame of' modernising government'/egovernment'. At this macro-level, CMs are an arena for contests about societal values and knowledge, where, for example, cost accounting competes with professional expert judgment as a measure of good service. In the case presented here, the marginalisation of local practitioner knowledge and practice is an instance of a societal phenomenon - an analogous conflict between cost accounting, ICT investment and expert knowledge is currently visible in the UK's health service. In the case presented here, such a macro-level epistemological contest may be a significant issue in any extended roll-out of mobile technologies.

Full 'mobilization' of the rapid response team will implicate a larger group of players; the council social services IT department; the social services directorate; the council leaders; the national health service (including: hospital trust managers; hospital trust IT departments; general practitioners); the outsource partner; the government (through policy initiatives); the providers of prostheses and other material aids to the housebound. We may therefore, tentatively, begin to ask whether more penetrating questions should be asked by those commissioning (and those investigating) service projects in digital cities - not 'How can we integrate service provision and save money and time?' but, 'Where and when does service happen? In whose interest? Who benefits, and how? Who loses, and how?' We suggest that a TAF analysis is an appropriate way to answer such questions.

\section{Acknowledgments}

We wish to acknowledge the help of anonymous interviewees in our fieldwork, and feedback from participants in a workshop on Digital Cities at the Communities and Technology meeting in Milan in June 2005 where an early version of this paper was presented.

\section{References}

Auge, M. (1995) Non-Places: Introduction to Anthropology of Supermodernity, Verso, London

Bijker, W (1997) Of bicycles, bakelites and bulbs: toward a theory of socio-technical change. Cambridge MA: MIT Press.

Cabinet Office (1999) Modernising Government. London: HMSO

City Council (2004). Internal document 
Crabtree, A. (2000) Remarks on the social organization of space and place. Journal of Mundane behaviour, at www.mundanebehavior.org/issues/vln $1 / \mathrm{crabtree}$.htm (Last consulted 31 March 2006)

Davenport, E. (2004). Project management and the elision of the social. In K. Horton \& E.Davenport (Eds), Understanding socio-technical action. Abstracts of a Workshop in School of Computing, Napier University, June 2003. Edinburgh: Napier University

Evaluation document. Council, 2004.

Fleck J (1993) Configurations: crystallizing contingency. International Journal of Human Factors in Manufacturing. 3, 1, 15-36.

Goffman, E. (1974). Frame analysis: an essay on the organization of experience. New York: Harper and Row.

Horton, K., Davenport, E. and Wood-Harper, T. (2005) Exploring socio-technical interaction with Rob Kling: five big ideas. Information, technology and people, 18(1), 52-67.

Iacono, S. and Kling, R. (1998) Computerization movements: the rise of the Internet and distant forms of work.. At http://rkcsi.indiana.edu/archive/kling/pubs/ Kling_comp.htm (Last consulted 27 March 2006)

Kling, R. \& Iacono, S. (1994). Computerization movements and the mobilization of support for computerization. Retrieved 12 February 2005 from http://www.slis.indian.edu/faculty/kling/pubs/MOBIL94C.htm (Last consulted 23 March 2006)

Kling, R. \& Scacchi, W. (1982). The web of computing: computer technology as social organization. Advances in Computers, 21, 1-90.

Lamb, R. \& Kling, R. (2003). Reconceptualizing Users as Social Actors in Information Systems Research. MIS Quarterly, 27(2), 197-235.

Massey, D B (1993) Power-geometry and a progressive sense of place. In Bird, J. et al. (eds.) Mapping the futures: local cultures, global change London: Routledge, 59 69.

Massey, D B (1993) Power-geometry and a progressive sense of place. In Bird, J. et al. (eds.) Mapping the futures: local cultures, global change London: Routledge, 59 69.

Orlikowski, W.J. \& Gash D.C. (1994). Technological frames: making sense of information technology in organizations. ACM Transactions on Information Systems, 12 (2), 174-207.

Snow, D. (2004). Framing processes, ideology and discursive fields. In D. Snow, S. Soule \& D. Kriesi (Eds.), Blackwell companion to social movements (pp. 380412). Oxford: Blackwell.

Snow, D. \& Benford, R. (1988) Ideology, frame resonance and participant mobilization. International Social Movement Research, 1, 197-217.

UK Cabinet Office. (1999). Modernising government. (Command paper) London: the Stationery Office. http://www.official-documents.co.uk/document $/ \mathrm{cm} 43 / 4310 . \mathrm{htm}$ (Last consulted 25 February 2005)

1 These issues observations have also been explored by SST and CSCW analysts; see contributions to Luff, Hindmarsh \&Heath, 1997).

2 Under European Union procurement rules, past performance cannot be considered when awarding public sector contracts.

3 User requirements analysis is an atavistic presence, however, in most of the approved methodologies for e-government systems development and design (it is, for example, a 
staple component of project management protocols in UK public sector (PRINCE2) and EC $5^{\text {th }}$ and $6^{\text {th }}$ Framework projects).

4 Interview with an informant.

5 Such multilevel rich explanation was a feature of Kling's work throughout his working life. The basis format for this 'web of computing' approach is provided in Kling \& Scacchi, 1982. And see Horton et al., 2005. 